\title{
Modelo Conceitual para Análise de Processos de Aquisição de Empresas Jornalísticas
}

CONCEPTUAL MODEL FOR ANALYSIS OF PROCESSES FOR ACQUISITION OF JOURNALISTIC COMPANIES

\section{Fabiano Rodrigues}

Doutor em Administração pela Universidade de São Paulo (USP). Mestre e bacharel em Engenharia de Produção pela USP. Professor adjunto e pesquisador no Programa de Mestrado Profissional em Produção Jornalística e Mercado (MPPJM) da Escola Superior de Propaganda e Marketing (ESPM-SP).

E-mail: frodrigues@espm.br

\section{Leandro Vieira}

Bacharel em Comunicação Social pelas Faculdades Integradas Alcântara Machado (FIAM) e mestrando em Produção Jornalística e Mercado pela Escola Superior de Propaganda e Marketing (ESPM), com pesquisa focada na área de Media Management.

E-mail: leandrovieira.40@gmail.com.

Recebido em 28/03/2018. Aprovado em 05/1 1/2018.

\section{Resumo}

Fusões eaquisições(F\&A), na cadeia devalor daindústria informativa, são opções estratégicas para renovação de competências. Este estudo desenvolve um modelo conceitual para análise de operações de aquisição, em especial aquelas em que o jornalismo não se configura como o core business da empresa compradora. Como contribuição teórica, o modelo possibilita a avaliação de potenciais tensões entre a visão orientada para negócio (compradora) e a orientação jornalística (comprada) nas três etapas de uma aquisição: negociação prévia, integração das operações e resultados derivados do novo arranjo organizacional.

Palavras-chave: Jornalismo. Fusões e Aquisições. Gestão de mídia.

\section{Abstract}

Mergers and acquisitions $(M \& A s)$ in the value chain of the information industry are strategic options for renewing competences. This study develops a conceptual model for the analysis of acquisition operations, especially those in which journalism is not the core business of the purchasing company. As a theoretical contribution, the model allows the evaluation of potential tensions between the business oriented vision (buyer) and the journalistic orientation (purchased) in the three stages of an acquisition: prior negotiation, integration of operations and results derived from the new organizational arrangement.

Keywords: Journalism. Merger and Acquisitions. Media Management. 


\section{Introdução}

Depois do Telecommunications Act of 1996, intensificaram-se os movimentos de fusões e aquisições (F\&A) de empresas de comunicação nos Estados Unidos. Isso porque uma das diretrizes trazidas pelo marco regulatório foi a possibilidade de se ter propriedade cruzada nos meios de comunicação (FCC, 2013). Decorrem daí as corridas por F\&A de diversos grupos empresariais do ramo, buscando consolidação como grandes conglomerados que controlam diversos canais de rádio e TV, ao mesmo tempo que têm em mãos indústrias cinematográficas e fonográficas, empresas de tecnologia, entre outras.

Alexander e Owers (2011) ressaltam que a década de 1990 foi aquela em que as operações de F\&A se sobressaltaram, impulsionadas pelas mudanças do marco regulatório, pelas condições econômicas gerais e por novos paradigmas tecnológicos. Croteau e Hoynes (2005) calculam que, com essa série de movimentações, só os anos 90 superaram a casa dos US\$ 300 bilhões em F\&A.

Soma-se a isso recente decisão do governo dos Estados Unidos que derrubou regra sobre a concentração de propriedades no setor de mídia. Datada de 1975, a restrição proibia que empresas tivessem jornais e redes de TV em um mesmo mercado (TREVISAN, 2017).

Não à toa, no topo da pirâmide dos maiores grupos empresariais de mídia norte-americanos estão empresas que se fizeram verdadeiros impérios por servirem-se do novo marco. Exemplos disso são o grupo Disney (proprietário de empresas como $\mathrm{ABC}$, ESPN e Disney Channel), Comcast (NBC Universal, Sony, AXN, Syfy, XFinity...), News Corp (The Wall Street Journal, Fox Filme Group, 20th Century Fox, Fox International Channels...), Turner Broadcasting System (CNN, Cartoon Network, TCM...), entre outros (DISNEY, 2018; COMCAST, 2017; NEWS CORP, 2017; TURNER, 2018).

Já no Brasil não se assistiu a vultosas fusões e aquisições no setor de mídia. Em linhas gerais, os maiores conglomerados do setor fizeram-se por meio de crescimento orgânico, ou seja, criando novos veículos de comunicação em vez de adquiri-los de outras empresas.

O Grupo Globo, por exemplo, maior grupo de mídia brasileiro, fez poucos movimentos de compra e venda de outras empresas do setor. O mais notório foi a aquisição integral do jornal Valor Econômico e do serviço de notícias Valor PRO, do qual o grupo, antes, detinha 50\% das ações (FOLHA DE S.PAULO, 2017).

O Grupo Folha também não fez grandes operações de compra e venda nas últimas décadas. Segundo maior conglomerado de mídia do País, o grupo se consolidou por meio da estruturação de novos negócios dentro de si próprio, sem recorrer a compra de outras 
empresas. Foi o caso do UOL e dos numerosos serviços que dele frutificaram (PagSeguro, Moderninha, e-mail, UOL Educação, entre outros). O grupo também criou editora própria, gráfica, revistas e uma operadora logística, com um processo de verticalização de suas operações (GRUPO FOLHA, 2017).

O Grupo Abril realizou diversificações não relacionadas ao core business jornalístico, explorando outras áreas, como a de prestação de serviços e marketplace (MEIO\&MENSAGEM, 2016).

O Grupo Record, quarto maior de mídia no Brasil, não fez movimentos de fusão e aquisição relevantes, e optou por vender parte de antigas subsidiárias, caso do jornal Hoje em Dia. Como acionista minoritário, o grupo adquiriu 10\% da rede CNT Bahia em 2014 (GUIMARÃES, 2013; UOL, 2014).

Proprietário de duas TVs abertas, seis canais por assinatura, onze emissoras de rádio e de dois jornais impressos, o Grupo Bandeirantes de Comunicação foi outro que cresceu com poucas aquisições. Única movimentação que fugiu ao padrão de expansão das empresas jornalísticas foi a joint venture com a Metro Internacional para a criação do Metro Jornal (BAND, 2017).

Enquanto os conglomerados consagrados seguem crescendo mais organicamente, percebe-se alguns movimentos de aquisições de empresas jornalísticas por empreendimentos que não possuem foco de atuação principal na indústria informativa.

O Grupo Hapvida, maior operador do ramo de saúde do Norte e Nordeste do Brasil, comprou os Diários Associados do Nordeste, operação que envolveu três emissoras de TV, quatro rádios e o jornal Diário de Pernambuco. Antes disso, o grupo já havia adquirido outras duas emissoras de TV - uma no Rio Grande do Norte e outra em Alagoas (FOLHA DE S.PAULO, 2015).

A XP Investimentos, corretora de valores controlada pelo grupo Itaú, comprou o portal financeiro InfoMoney. Na ocasião do anúncio, a XP afirmou que investiria cerca de R \$ 5 milhões na modernização do portal e, como resultado, esperaria triplicar o número de correntistas e quintuplicar a audiência de seus produtos de conteúdo (KAHIL, 2011).

Também do ramo financeiro, a consultoria Empiricus comprou metade de um dos maiores blogs políticos do país, O Antagonista (EMPIRICUS, 2016).

Nesses últimos três casos, em particular, uma lógica chama a atenção: as empresas compradoras nada têm a ver com o ramo jornalístico. Tratam-se de agentes exógenos à realidade da práxis da atividade, mas que viram no setor certa atratividade e, para isso, serviram-se do processo de fusões e aquisições para viabilizar o negócio. 
Processos de F\&A geram, naturalmente, fricções entre as partes envolvidas. Quando empresas de jornalismo são envolvidas nesses negócios e seus controladores serão companhias que não guardam relação com o fazer jornalístico, tem-se, então, potenciais tensões entre o lado business e o jornalismo.

Tais processos fazem parte dos estudos sobre Media Management, que abrangem temas como: gestão estratégica, economia das organizações, inovação e difusão de inovações, eficiência e cultura organizacional, novos arranjos organizacionais e novos processos intra e entre organizações na cadeia de valor da indústria informativa (MIERZJEWSKA; HOLLIFIELD, 2006; ALBARRAN, 2014; RODRIGUES; ROCHA; CAPOANO, 2017).

Este artigo pretende contribuir com o campo de estudos jornalísticos a partir do desenvolvimento de um modelo conceitual de aquisições para que o processo e potenciais conflitos sejam avaliados. Como contribuição teórica, o modelo possibilita a avaliação de potenciais tensões entre a visão orientada para negócio (compradora) e a orientação jornalística (comprada) nas três etapas de uma aquisição: negociação prévia, integração das operações e resultados derivados do novo arranjo organizacional.

Assim, o modelo conceitual, elaborado neste estudo teórico a partir da articulação de referências do campo da Administração e do Jornalismo (com foco em pesquisas sobre Media Management), visa mapear os possíveis conflitos, provocar reflexões nos atores envolvidos em processos de F\&A e em pesquisadores da área, bem como avançar no conhecimento sobre o mercado jornalístico, os impasses editoriais, o papel da jornalista e a própria filosofia que modela a profissão.

Embora muito se fale a respeito de estratégias para as empresas se inserirem nesse novo mundo, como novos formatos, conteúdos diferenciados, meios de interação mais sofisticados - o newsmaking, em si -, ainda há espaço e necessidade para debate sobre arranjos organizacionais que suportem tais práticas.

\section{Fusões e Aquisições}

Segundo a Lei das Sociedades Anônimas (Lei n 6.404/76), "a fusão é a operação pela qual se unem duas ou mais sociedades para formar sociedade nova, que lhes sucederá em todos os direitos e obrigações" (PLANALTO, 1976). Também é definida como o resultado de combinação de duas organizações in- 
dependentes, dando origem a uma terceira e nova entidade (DUARTE; SAYÃO; TANURE, 2006). A aquisição, por sua vez, é o processo de compra do controle de uma empresa por outra, visando a tornar a adquirida uma subsidiária de seu portfólio. Nessa situação, a empresa adquirida tem de prestar contas à administração da adquirente (HITT et al., 2011).

Hitt, Ireland e Hoskison (2008) dizem que fusão é a integração da operação de duas empresas em base relativamente igual, por terem, juntas, recursos e capacidades que podem criar uma vantagem competitiva mais significativa; ao passo que a aquisição é uma estratégia em que uma companhia compra participação de outra com o intuito de alavancar competências e auferir vantagens competitivas.

Tanto as fusões como as aquisições podem ser horizontais, verticais, congêneres e conglomerado, a depender da natureza das companhias que se unirão e de seus produtos e/ou serviços (SILVA et al., 2010).

Os processos horizontais ocorrem quando há compra de uma empresa por outra que atue no mesmo ramo de sua atividade. O propósito é expandir as atividades em um sentido tal que as companhias conheçam os problemas umas das outras, bem como entendam seus respectivos ramos de atuação. Nessa modalidade, as aquisições potencializam o poder de mercado de uma empresa ao explorar a coesão, baseando-se em custos e receitas (CAPRON; PRISTE, 2002). Contribuem para os melhores resultados dessas operações empresas cuja estratégia, cujos modos de administrar e padrões de alocação de recursos se assemelhem.

Nas F\&A verticais há duas subclassificações. Nas progressivas, a empresa adquirente incorpora outra que compra seus produtos; nas regressivas, quando a comprada é fornecedora da adquirente. Como exemplo, pode-se citar uma fábrica de bebidas que compra um supermercado. Em linhas gerais, ocorrem aquisições verticais quando uma empresa passa a ter a posse de seus canais de venda e/ou daqueles que lhe fornecem produtos e serviços. Hitt, Harrison e Ireland (2001) afirmam que as aquisições verticais procuram controlar parte da cadeia de valor. Para isso, pode-se recorrer tanto às aquisições regressivas, progressivas como àquelas que buscam incorporar organizações que já detêm partes importantes de um determinado elo da cadeia que interessa à adquirente, fazendo com que essa operação lhe adicione poder de mercado.

Há, ainda, as aquisições congêneres ou relacionadas -- pelas quais duas empresas de uma mesma indústria ou segmento se envolvem, conquanto não trabalhem 
na mesma linha de negócios (CAMARGOS; COUTINHO, 2008); e as de conglomerado ou não relacionadas, em que duas companhias que atuam em diferentes ramos se envolvem visando à diversificação de seus negócios às economias de escala e escopo (CASTRO, 2010).

Operações de fusão e aquisição tem como base a expectativa de que a empresa resultante da combinação gere valores maiores do que aquele que seria obtido se cada uma delas permanecesse atuando isoladamente. Em suma, trata-se de uma estratégia de crescimento rápido, pois parte-se do princípio de que "um mais um é maior do que dois" (CASTRO, 2010).

Dentre as principais razões que motivam as F\&A, Bender e Ward (2005) destacam o suporte ao crescimento da criação de valor que não seria alcançada por meios orgânicos; complementação da estratégia de negócios através do preenchimento de hiatos no portfólio de produtos; alcance de segmentos mercadológicos, área geográfica ou tecnologias específicas; ou, ainda, criar um óbice para que um competidor faça a aquisição.

\section{Ełapas dos Processos de Fusões e Aquisições}

Classicamente, a literatura sobre estratégia corporativa divide as etapas de aquisição de uma empresa em três fases: antes da compra, em que são analisadas dimensões como similaridade e relação entre os agentes e seus mercados, potenciais de complementariedade, compatibilidade cultural, ambientes externos, internos e recursos organizacionais; fase de integração, em que se consideram choques culturais pela junção de operações, formação de novas competências e novos processos para geração de valor; e a pós-aquisição, onde são sopesados pontos relacionados à mensuração de resultados, criação de valores para clientes, vantagem competitiva obtida, benefícios à empresa, aos colaboradores e à sociedade (HITT et al., 2011; BAUER; MATZLER, 2014).

Para atendimento do objetivo deste artigo, adotou-se a lógica I-P-O (input-processo-output) para a análise das fases do processo de aquisição de uma empresa. Segundo Rodrigues (2010), a lógica I-P-O é o framework dominante para análise de processos decisórios. Este frame destaca "a influência dos inputs no processo e a influência deste no desempenho (output), revelam e analisam relações lineares, com influências sequenciais entre I-P e/ou P-O e/ou I-O.” 
Hitt et al. (2011) afirmam que essa análise proporciona uma visão multinível e rica das estratégias empresariais por incorporar fatores ambientais, organizacionais e individuais no processo dinâmico da busca por oportunidades e vantagens competitivas.

O input diz respeito ao fluxo de informações e materiais extraídos de um determinado ambiente que são introduzidos para dentro de um processo. O processo engloba as etapas requeridas para a transformação do que se angariou no input. O output são os dados, resultados e materiais originados do processo de transformação.

O primeiro fator analisado pela I-P-O, o input, dentro do escopo deste estudo, compreende aspectos de diferentes níveis na fase de negociações prévias, como os fatores ambientais concernentes às companhias envolvidas em uma operação de F\&A, características e especificidades das organizações arroladas e os recursos de que cada uma dispõe. São, em suma, os elementos que motivam e/ou despertam o interesse estratégico para uma F\&A.

O segundo, processo, dá conta de examinar como os recursos das empresas e suas ações empreendedoras são orquestradas para que se valorizem. Diz respeito, na esfera interna, do "como fazer". É aplicado para a análise de como se dá a integração entre as empresas envolvidas em uma F\&A, levando em conta, em seus respectivos níveis, a exploração dos novos recursos de ambas as firmas que, combinados, adicionam-lhe potencial de valorização e renovação de competências.-

O último, output, focaliza os resultados oriundos das etapas anteriores, com uma lente mais concentrada na criação de valores para a sociedade, para o conjunto das duas empresas e os benefícios criados para cada uma delas individualmente. Entram nessa equação melhorias societárias, riqueza, conhecimento e oportunidades.

A Figura 1 sintetiza as etapas do processo de fusão e aquisição, customizadas para o cenário da indústria informativa.

O esquema foi concebido com base em revisão bibliográfica, que combina tanto os conceitos, características e etapas de processos de fusões e aquisições (HITT; HARRISON; IRELAND, 2001; HITT; IRELAND; HOSKISON, 2008; HITT et al., 2011; BARROS; CANÇADO, 2003; BENDER; WARD, 2005; SILVA et al., 2010; DUARTE; SAYÃO; TANURE, 2006; MARKS; MIRVIS, 2010), quanto a lógica de operação e desafios de gestão inerentes às empresas jornalísticas, itens que serão explorados na seção 4 do presente artigo teórico. 
Figura 1 - Etapas do processo de F\&A no cenário da indústria informativa

\begin{tabular}{|c|c|c|}
\hline $\begin{array}{l}\quad \begin{array}{l}\quad \text { INPUT } \\
\quad \text { (Negociações pré } \\
\quad \text { F\&A) }\end{array} \\
\text { - Motivações para a } \\
\text { negociação } \\
\text { - Análise de ambiente } \\
\text { interno e externo } \\
\text { - Diagnóstico das } \\
\text { competências atuais e } \\
\text { das competências-alvo } \\
\text { - Vantagens } \\
\text { competitivas a explorar } \\
\text { - Orientação de } \\
\text { mercado e editorial }\end{array}$ & $\begin{array}{l}\quad \begin{array}{c}\text { PROCESSO } \\
\text { (Integraçãao das } \\
\text { operações) }\end{array} \\
\text { - Criação de valor via } \\
\text { sinergias } \\
\text { - Criação, manutenção e } \\
\text { descarte de } \\
\text { recursos/competências } \\
\text { - Conciliação de culturas } \\
\text { distintas } \\
\text { - Novos processos de } \\
\text { gestão } \\
\text { - Mudanças na produção } \\
\text { jornalística } \\
\text { - Investimentos na } \\
\text { operação da adquirida }\end{array}$ & $\begin{array}{l}\quad \begin{array}{l}\text { OUTPUT } \\
\text { (Resultados derivados da } \\
\multicolumn{1}{c}{\text { F\&A) }}\end{array} \\
\text { - Benefícios individuais, } \\
\text { organizacionais, ao mercado } \\
\text { e à sociedade } \\
\text { - Novo modelo de gestão e de } \\
\text { negócios } \\
\text { - Competências resultantes e } \\
\text { potenciais alterações na } \\
\text { cadeia de valor } \\
\text { - Produto jornalístico } \\
\text { resultante } \\
\text { - Resultados da operação x } \\
\text { independência editorial }\end{array}$ \\
\hline
\end{tabular}

Fonte: Elaborado pelos autores (2017)

Das três etapas, a que mais tem potencial de gerar tensões é a da integração (processo). É nela que os recursos e processos das empresas envolvidas são integrados na prática, por meio da execução das estratégias traçadas para a F\&A.

Barros e Cançado (2003) lembram que a integração é a fase de ajuste de planejamento, estratégia, pessoas, processos e culturas. Como será feito isso é delineado pelos motivos que nortearam a compra, pelo porte das companhias envolvidas, pela capacidade gerencial da adquirente, pela necessidade de manutenção do corpo social e pela situação financeira da empresa comprada. Trata-se de um processo complexo e com riscos a ambas as partes.

Na incorporação de duas companhias, há o encontro entre duas culturas diferentes, e, cada qual, com seus próprios pressupostos - valores, crenças, lentes peculiares de leitura da realidade, organização, processos para realização de suas atividades etc. Marks e Mirvis (2010) sublinham que o processo de sedimentação da nova cultura pode levar de sete a dez anos.

Inseguranças, confusões internas, resistências construídas por colaboradores das companhias envolvidas, eventuais demissões e substituições de pessoas são questões a serem enfrentadas nesta fase do processo. Duarte, Sayão e Tanure (2006) elencam a aversão das pessoas a grandes mudanças, sentimento de insegurança, confusão e desmotivação como óbices a serem transpostos na integração. Dizem que não basta substituir pessoas que não se enquadrem no novo sistema e valores, uma vez que cada empresa tem suas idiossincrasias na interpretação de realidades, crenças particulares, processos e modos de fazer as coisas acontecerem. 


\section{F\&A como Resposta Possível aos Desafios do Jornalismo}

A evolução tecnológica, com repercussões intensas na indústria informativa - inclusive, sendo a motivação para muitas operações de F\&A --, implicou, nos últimos anos, mudanças profundas em uma indústria que até pouco tempo cumpria um papel cujo exercício era de predomínio praticamente exclusivo: o monopólio e a difusão de informação. Anderson, Bell e Shirky (2013), em alusão ao setor jornalístico, afirmam que a similitude de métodos entre um grupo relativamente pequeno e uniforme de empresas e incapacidade de alguém de fora desse grupo de criar um produto competitivo eram barreiras de entrada de novos agentes nesse mercado.

Com impressionante velocidade, grandes companhias de jornalismo viram ruir essas muralhas. Na esteira do avanço das tecnologias de informação e comunicação, veio a liberdade de os diversos atores da sociedade de interagir entre si no ambiente virtual e de produzir notícia e conhecimento. As limitações do velho modelo de transmissão de notícias, em que um falava para milhões, fragmentaram-se, e, hoje, milhões falam para milhões.

Deuze e Witschge (2016) chamam esse fenômeno de sociedade redacional - aquele em que as práticas de uma redação jornalística são necessárias para a sobrevivência das pessoas em um mundo digitalizado. As ferramentas de ofício do jornalista não lhes são mais exclusivas. Agora, seu uso está disseminado pela e na sociedade.

A sociedade redacional é um estágio posterior ao da sociedade da informação, em que os cidadãos teriam acesso a múltiplas informações. Na sociedade redacional, ter acesso a informação ou produzir sentidos dela decorrentes não é mais suficiente. As pessoas, agora, precisam de competências e habilidades jornalísticas, como saber coletar e processar grandes volumes de informações, lapidar dados, saber como usar a informação de que tem poder, entre outros. Em certa medida, não deixar de ser uma comoditização do fazer jornalístico, desvalorizando-o institucionalmente.

Picard (2009) diz que esse novo ambiente pode afetar o valor oferecido pelo jornalista, tanto para sua própria organização quanto para a sociedade, justamente em decorrência do poder que os indivíduos ganharam na criação e distribuição de informações. Se há mais pessoas fazendo o que só jornalistas faziam, tem-se, inevitavelmente, a potencial desvalorização, inclusive econômica, da prática jornalista.

Diante das premências de as organizações jornalísticas darem respostas a esse novo cenário, e levando em conta as peculiaridades das fusões e aquisições, considerá-las como possível alternativa às demandas atuais merecem reflexões. F\&A podem vir a 
significar questão de vida ou morte para diversos empreendimentos na cadeia de valor da indústria informativa, comprometidos pela avalanche das novas plataformas e meios. Exemplo disso pode ser visto, particularmente, em empresas de publicações impressas.

Duchessi e Biswas (2013) explicam como parte dessas companhias investiram na compra de empresas de tecnologia como meio de resposta às mudanças de mercado. De acordo com os autores, de 2002 a 2007, em nível global, empresas de publicações impressas adquiriram mais de 350 empresas do setor de tecnologia da informação. O impacto dessas junções foi sentido no âmbito da criação de conteúdos digitais, distribuição eletrônica e novos serviços.

A emergência da convergência digital requer que reconheçamos a existência de pontos comuns entre as empresas de publicações impressas e as de serviços de TI. A convergência digital é a combinação ou fusão de aspectos digitais que, antes, eram totalmente distintos. Isso permite que as companhias aprimorem seus recursos, serviços e produtos e ampliem o leque de opções a novas indústrias e mercados, desfazendo as fronteiras convencionais entre esses setores. (DUCHESSI; BISWAS, 2013, p. 213, tradução nossa).

Lembram os autores que empresas operantes em indústrias que restringem o crescimento e têm incertezas no ramo tecnológico, geralmente, recorrem às F\&A não relacionadas. Trata-se do reconhecimento de que, elas mesmas, por si sós, não atingirão patamares mais elevados de desenvolvimento, obstando a diversificação de negócios. Frente isso, optam por adquirir outras empresas em indústrias completamente diferentes, a fim de preencher essa lacuna.

Essas movimentações modernizadoras vão ao encontro do que Anderson, Bell e Shirky (2013) relatam. De acordo com eles, empresas jornalísticas que investiram em tecnologia registraram altos ganhos em produtividade. Ressaltam, entretanto, que o sucesso não veio apenas do investimento puro e simples; deu-se juntamente com mudanças de processos. "Viraram outro tipo de organização. Já aquelas que simplesmente instalaram computadores sem mexer em processos que já existiam não registraram nenhum avanço evidente em rendimento ou eficiência" (p. 37).

\section{Modelo Conceitual de F\&A com Introdução de Tensões Jornalisticas}

Para auxiliar pesquisadores do campo jornalístico na avaliação de F\&A, o presente estudo propõe um modelo conceitual que incorpora as etapas do processo segundo a 
lógica I-P-O (input, process e output), conforme apresentado pela Figura 1, e sua ligação com potenciais tensões geradas entre as empresas envolvidas em cada etapa, focando-se em eventuais atritos entre o lado jornalístico e a visão orientada para o negócio.

Esses atritos e suas derivações estão identificados na literatura sobre media management, amparados em autores como Picard (2004, 2009); Nevéu (2006); Anderson, Bell e Shirky (2013); Andersson e Wiik (2013); Evetts (2005); Siegert, Gerth e Rademacher (2011) e Wiik (2010).

Figura 2 - Etapas do processo de F\&A e potenciais tensões

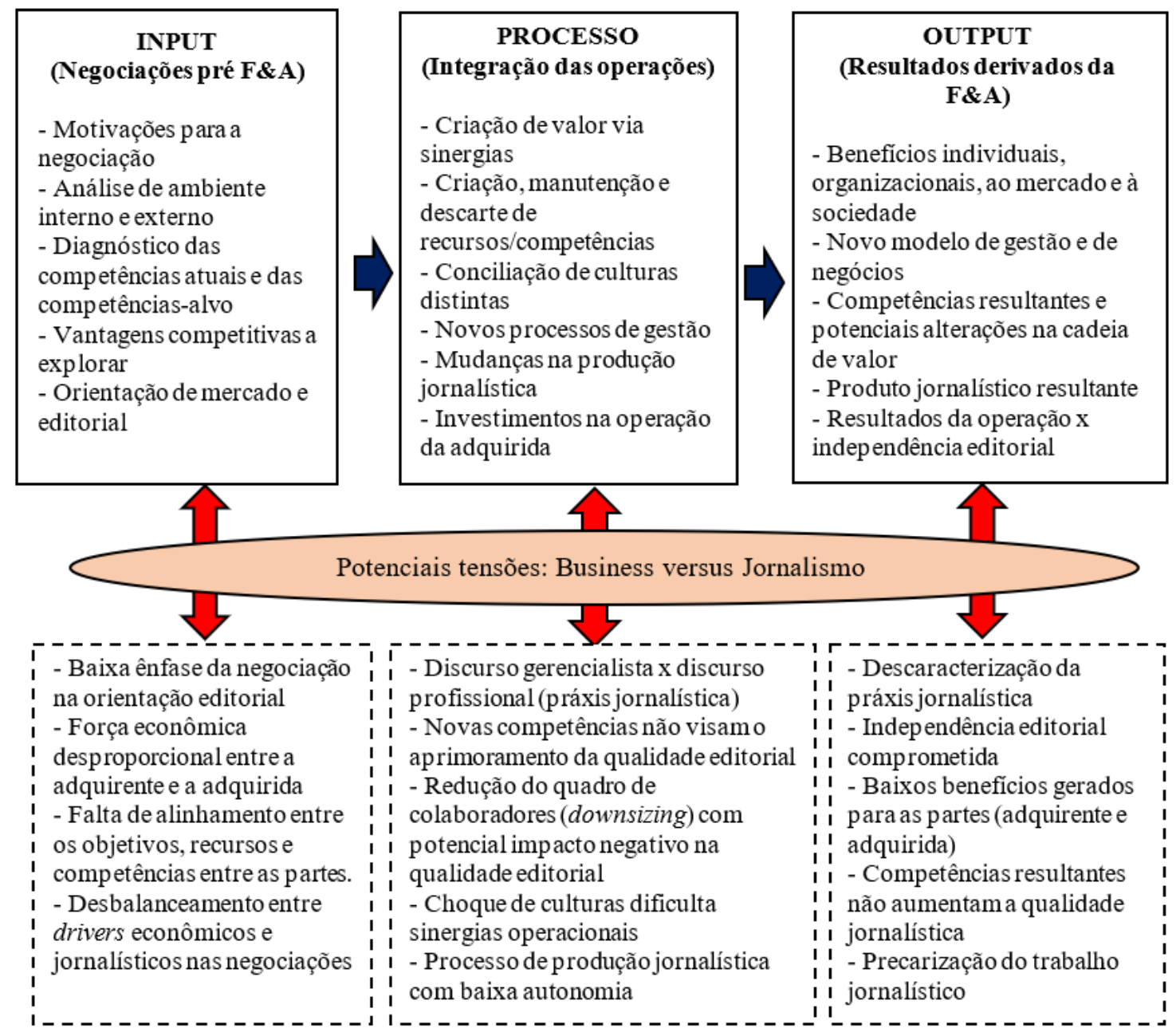

Fonte: Elaborado pelos autores (2017)

Por muito tempo, os jornalistas pareciam distantes da realidade econômica de suas próprias empresas. A autonomia com que sempre contaram se confundia com uma licença para que seu trabalho e seus esforços fossem direcionados apenas à produção de notícia. 
Nesse sentido, em linhas gerais, pouco os jornalistas deixavam-se contagiar por eventuais metas concebidas no plano gerencial ou da alta gestão da empresa.

As placas tectônicas dessa realidade começam a se desnivelar, descortinando aos profissionais, em especial àqueles que chefiam redações ou equipes de jornalistas, uma nova forma de encarar suas atividades e suas funções dentro das organizações jornalísticas (ANDERSON; BELL; SHIRKY, 2013; ANDERSSON; WIIK, 2013; BELL, et al., 2017; NEVEU, 2006; PICARD, 2004, 2009).

Nesse contexto, principalmente na última década, muitas redações viram se acentuar a negociação entre duas forças dentro do negócio jornalístico, conforme apontam Andersson e Wiik (2013): o discurso profissional e o discurso gerencialista (managerial discourse). O primeiro caracteriza a identidade pelo ideal jornalístico, cujas tônicas residem na autonomia profissional e na satisfação de uma autorregulação; o segundo esboça a globalização dos valores econômicos nos mercados de trabalho, vislumbrando modelos organizacionais e introduzindo um pensamento comum para muitas indústrias: envolver os indivíduos das empresas em uma perspectiva empreendedora. Assim, as organizações jornalísticas funcionariam em uma zona fronteiriça, tensionada, entre a política da profissão e o mercado, combinando duas diferentes lógicas em sua governança.

Ao discorrer sobre a realidade dos jornais na Suécia, Andersson e Wiik (2013) comentam que uma série de fusões e aquisições havidas naquele país - motivadas pela crise de financiamento e rareamento da publicidade em veículos impressos -- constituírem-se em oportunidades para uma nova lógica de comando editorial.

Desde a década de 1950, os departamentos das empresas, como o editorial, a administração, as vendas, a tecnologia e a distribuição, foram governados por uma liderança de dois níveis: uma liderada pelo diretor de redação, a outra pelo CEO (Ohlsson, 2012). Como as condições estruturais da mídia [...] mudaram ao longo das últimas décadas, a perspectiva econômica espraiou-se cada vez mais das unidades administrativas e econômicas para as redações. Um exemplo é encontrado na aplicação do termo "indústria", usado frequentemente para descrever o trabalho nas organizações de mídia (Ohlsson 2012). O uso deste termo indica claramente que os meios de comunicação são vistos como empresas que produzem e vendem produtos jornalísticos para públicos específicos em mercados específicos. Embora a liderança de dois níveis ainda exista em muitos jornais, é claro que as perspectivas gerencialistas estão cada vez mais integradas ao trabalho dos editores-chefes. [...] A linha previamente clara entre jornalismo e gestão administrativa que surgiu durante os primeiros dias da profissionalização jornalística deve, portanto, ser considerada muito menos distinta hoje (Djerf Pierre e Weibull 2009) (ANDERSSON; WIIK, 2013, p. 707, tradução e grifos nossos). 
A separação entre as redações e o lado administrativo das empresas sempre foi cômoda aos jornalistas, pois, dessa forma, sentiam-se estáveis em suas posições, livres que sempre foram das performances financeiras de suas companhias. Para isso, fincaram convicções de que o valor de seus trabalhos não poderia ser medido pela visão e métricas de negócios. O serviço em prol da democracia, do interesse público, da verdade, de vigia do poder, entre outros, são algumas das palavras que sempre vêm à superfície das discussões quando se fala da função social do jornalista.

É claro que os jornalistas não querem estar no mercado de trabalho contemporâneo, e muito menos o mercado de informação altamente competitivo. Eles preferem justificar o valor que criam nos termos da filosofia moral do valor instrumental. A maioria acredita que o que eles fazem é tão intrinsecamente bom e que eles devem ser compensados para fazê-lo, mesmo que não produza receita. Este ponto de vista é incorporado no profissionalismo do jornalismo, especialmente nos esforços para melhorar a prática e atividades comerciais e editoriais separadas que desenvolveram ao longo do século 20 e foram projetados para proteger a criação de valor moral. No entanto, os jornalistas também usaram o profissionalismo para criar empregos e condições econômicas relativamente confortáveis para si próprios, evitar qualquer responsabilidade pelo desempenho de suas empresas e proteger-se das mudanças no mercado (PICARD, 2004, p.5, tradução nossa).

Siegert, Gerth e Rademacher (2011) procuram desmistificar o consenso de que o crescimento em importância da orientação comercial nas companhias de mídia implica o debacle da qualidade editorial. Reconhecem que uma das principais consequências é a mudança da natureza do conteúdo veículo, o que não significa, necessariamente, precarização do noticiário.

Quaisquer mudanças demandadas do perfil do profissional do jornalismo ou da atividade jornalística em si é razão para que se associe o debate às expectativas democráticas que lhes são inerentes. Sem a visão tradicional que envolve o jornalismo, poder-se-ia encará-lo apenas como mais um negócio dentre tantos outros existentes no mundo - o que não ocorre. Fomentadas pela ideologia, as preocupações sobre possíveis degenerações do jornalismo partem do pressuposto de que os pilares tradicionais da atividade são intocáveis (WIIK, 2010).

Novas lógicas de gestão, novos modelos de negócios, novas demandas em relação à atividade, no entanto, são arrostadas, não raro, como golpes de morte no bom jornalismo. 
As implicações da nova situação econômica para os jornalistas significam uma série de condições de mudança em seus trabalhos e na criação de suas identidades. A concentração de propriedade de mídia e as fusões envolvem esforços de gerenciamento para integrar diferentes departamentos e seções de acordo com as estratégias de comando top-down. [...] planos de longo alcance e ambições futuristas de executivos são muitas vezes interpretados por jornalistas como críticas injustas ao seu trabalho. Os resultados são conflito, moral danificada e nostalgia de "bons velhos tempos" entre repórteres e editores, e, como resultado, resistência às mudanças propostas (Deuze, 2007, Gade, 2004, Gade e Perry, 2003, Sveningsson, 1999). A falta de inclinação dos jornalistas a reconhecer forças econômicas e novas ideias é uma consequência natural de suas lutas profissionais (WIIK, 2010, p. 36).

Evetts (2005) pontua a existência de dois tipos de discursos que surgem da tensão entre a nova realidade do jornalismo e entre sua visão ortodoxa: o discurso do profissionalismo organizacional e o do ocupacional. O primeiro diz respeito ao discurso gerencialista, procedente de uma visão top-down. Está ligado à definição e cumprimento de metas, revisões de desempenho e, em última análise, na sustentabilidade financeira da empresa. Já o discurso ocupacional circula em grupos profissionais, e leva em conta valores e princípios da profissão. Encarregam-se de refletir sobre a realidade sob presságios mais humanísticos.

Mesmo que, teoricamente, esses dois discursos não constituam um único, profissionais do jornalismo negociam diariamente com ambos. Wiik (2010) afirma que, paulatinamente, a visão gerencialista será mais incorporada ao cotidiano do jornalismo, ainda que de maneira imperceptível. "Seria um resultado lógico da cooperação entre o seu profissionalismo e os esforços gerenciais que se tornam cada vez mais tangíveis" (p. 55-56).

As decisões editoriais e as tensões existentes nas empresas de jornalismo terão de ser enfrentadas sob um novo guarda-chuva lógico. A liberdade do jornalismo e necessária autonomia para o exercício da profissão são pontos que continuarão na pauta do novo ecossistema, porém, de forma negociada institucional, organizacional e socialmente.

Tem-se, com cada vez mais frequência, o hibridismo das relações entre o campo editorial e o comercial das empresas. No jornalismo, nesse quesito, figuram questões como o papel da gestão da redação, o que é o produto jornalístico, a autonomia profissional, a desvalorização da técnica jornalística, abertura das redações à participação das áreas de marketing e comercial, novo papel do jornalista, entre outros. Pelo lado gerencialista, tem-se sua maior presença nas decisões editoriais, acurácia nas relações na redação, de modo a não eclipsar o fazer jornalístico, visão empreendedora (inclusive, encarregando-se de inculcá-la nos profissionais de redação), procura pela satisfação da audiência, entre outros (ANDERSSON; WIIK, 2013). 


\section{Considerações Finais}

A gestão jornalística tem sofrido inúmeras mudanças nas últimas décadas. Provocadas pela crise de financiamento, as empresas do ramo, com fins lucrativos, veem-se diante de uma realidade inescapável: dar mais abertura à mentalidade gerencialista, de business dentro das redações.

Ainda hoje, tal alvitre pode soar como uma ameaça às liberdades das quais o jornalismo sempre gozou em nome do serviço que prestam à democracia e às sociedades em que tem liberdade de expressão. Entretanto, há, sim, espaço para que a cultura empreendedora se esparja pelas redações, suportando novos modelos de fazer jornalismo, em que o comprometimento com metas que dão sustentabilidade financeira ao negócio não signifique, automaticamente, sacrificar o jornalismo de qualidade.

Como exposto neste estudo, oportunidade para a concretização desse espírito são as operações de fusões e aquisições na indústria informativa. Operações dessa natureza têm despontando no Brasil, e com um aspecto interessante: empresas que nada têm a ver com o jornalismo estão adquirindo empresas essencialmente jornalísticas, como o caso da aquisição da InfoMoney pela XP Investimentos e do blog político Antagonista pela Empiricus.

O modelo conceitual formulado neste estudo (Figura 02) contribui para a ampliação de pesquisas sobre aquisição de empresas jornalísticas por empresas não jornalísticas, pois incorpora as etapas do processo de aquisição (I-P-O) e as potenciais tensões entre a qualidade jornalística e uma orientação mais gerencialista, voltada para métricas de negócio e de resultados.

São bem-vindos trabalhos futuros, de natureza qualitativa ou quantitativa, que incorporem todas as etapas do modelo ou algumas de suas ligações, como o impacto das negociações prévias no processo de integração, com a perspectiva hibrida (business versus jornalismo).

Como contribuição adicional, o artigo proposto visa fortalecer o campo de estudos sobre Media Management em território nacional, campo multidisciplinar composto por contribuições de várias áreas de conhecimento, tais como Comunicação, Jornalismo, Administração, Economia e Tecnologia da Informação (ALBARRAN, 2014; RODRIGUES; ROCHA; CAPOANO, 2017). 


\section{Referências}

ALBARRAN, A. B. Assessing the Field of Media Management and Economics Research: Looking Back, Looking Forward. Palabra Clave. v. 17, n.4, p. 1025-1040, 2014.

ALEXANDER, A.; OWERS, J. Market Reactions to Merger, Acquisition, and Divesture Announcements in the Media Industries. International Journal on Media Management. v. 13, 2011, p. 253-276.

ANDERSON, C.W., BELL, E., SHIRKY, C. Jornalismo Pós-Industrial: adaptação aos novos tempos. Revista de Jornalismo ESPM, São Paulo, n. 51, abr-jun. 2013. Disponível em: <http:// www.espm.br/download/2012_revista_jornalismo/Revista_de_Jornalismo_ESPM_5/files/assets/ common/downloads/REVISTA_5.pdf>. Acesso em: 26 dez. 2017.

ANDERSSON, U.; WIIK, J. Journalism Meets Management: Changing leadership in Swedish News organizations. Journalism Practice. v. 7, n. 6, p. 705-719, abri1/2013.

BAND. Linha do tempo. Band.com. Disponível em: < http://www.band.uol.com.br/grupo/historia.asp>. Acesso em: 26 dez. 2017.

BARROS, B. T.; CANÇADO, V. L. Aquisições: um perfil das operações no Brasil. Nova Lima: Fundação Dom Cabral, 2003.

BAUER, F.; MATZLER, K. Antecedents of M\&A Success: yhe role of strategic complementarity, cultural fit, and degree and speed of integration. Strategic Management Journal, v. 35, p. 269291,2014

BELL, E., TAYLOR, O., BROWN, P., HAUKA, C., RASHIDIAN, N. A Imprensa nas Plataformas. Revista de Jornalismo ESPM. n. 20, ano 6, p. 48-83. Jul/dez 2017.

BENDER, R.; WARD, K. Corporate Financial Strategy. 2nd. ed. U.S.A.: Butterworth-Heinemann, 2005.

CAMARGOS, M., A.; COUTINHO, E., S. A Teoria da Firma e a Fundamentação Teórica para Fusões e Aquisições: uma análise de suas interfaces. RAC-Eletrônica, v.2, n. 2, p. 273-295, maio/agosto, 2008.

CAPRON, L.; PRISTE, N. When do Acquires Earn Abnormal Returns? Strategic Journal Management, v. 23, n. 9, p. 781-794, 2002. 
CASTRO, D., M., F., de. Criação de Valor em Fusões e Aquisições. Dissertação de mestrado em Administração. Universidade de São Paulo, São Paulo, 2010.

COMCAST CORPORATION. Connecting You to What Matters. Disponível em: $<$ https://corporate.comcast.com/company >. Acesso em: 29 dez. 2017.

CROTEAU, D. R.; HOYNES, W. D. The Business of Media: corporate media and the public interest. $2^{\mathrm{a}}$ ed. SAGE Publications, 2005.

DEUZE, M., WITSCHGE, T. O que o jornalismo está se tornando. Revista Parágrafo, v.5, n.2, p. 7-20, jul/dez 2016 .

DISNEY. About the Wall Disney Company. Disponível em: <https://www.thewaltdisneycompany.com/about/\#our-businesses>. Acesso em: 22 out 2018.

DUARTE, R.G.; SAYÃO, A.C.M.; TANURE, B. Mudanças na Cultura Pós-Aquisição: o caso da Empresa Alfa. In: ENCONTRO DA ANPAD, 30., 2006. Anais [...]. Salvador, 2006.

DUCHESSI, P., BISWAS, R. Value Creation in Publishing Industry: the impact of acquiring IT services firms between 2002 and 2007. International Journal on Media Management. v. 15, p. 211-218, dez/2013.

EMPIRICUS. Encontramos um inimigo e nos juntamos a ele. Empiricus. São Paulo, 2016. Disponível em: $<$ https://www.empiricus.com.br/blog/encontramos-um-inimigo-e-nos-juntamos-a-ele/>. Acesso em: 26 dez. 2017.

EVETTS, J. The Management of Professionalism: a contemporary paradox. School of Sociology and Social Policy. University of Nottingham. Londres, 2005.

FCC. Federal Communications Commission. 2013. Disponível em: <https://www.fcc.gov/general/telecommunications-act-1996>. Acesso: em 15 dez. 2017.

FOLHA DE S.PAULO. Cade aprova venda dos Diários Associados do Nordeste. Folha de S.Paulo. São Paulo, 27 jan. 2015. Mercado. Disponível em: < http://www1.folha.uol.com.br/mercado/2015/01/1581221-cade-aprova-venda-dos-diarios-associados-do-nordeste.shtml>. Acesso em: 26 dez. 2017. 
FOLHA DE S.PAULO. Grupo Globo adquire controle do jornal 'Valor Econômico'. Folha de S.Paulo, São Paulo, 13 set. 2017. Mercado. Disponível em: <http://www1.folha.uol.com.br/mercado/2016/09/1812854-grupo-globo-adquire-controle-do-jornal-valor-economico.shtml>. Acesso em: 26 dez. 2017.

GRUPO FOLHA. Conheça o grupo. Grupo Folha. São Paulo. Disponível em: <http://www1. folha.uol.com.br/institucional/>. Acesso em: $26 \mathrm{dez} .2017$.

GUIMARÃES, S. P. Rede Record vende jornal Hoje em Dia para Grupo Bel. Exame.com. 12 set. 2013. Negócios. Disponível em: < https://exame.abril.com.br/negocios/rede-record-vende-jornal-hoje-em-dia-para-grupo-bel/>. Acesso em: 26 dez. 2017.

HITT, M. A.; HARRISON, J. S.; IRELAND, R. D. Mergers and Acquisitions: a guide to creating value for stakeholders. Oxford University Press, 2001.

HITT, M. A.; IRELAND, R. D.; HOSKISON, R. E. Administração Estratégica: competitividade e globalização. 2. ed. São Paulo: Thomson Learning, 2008.

HITT, M. A.; IRELAND, R. D.; SIRMON, D. G.; THAMS, C. A. Strategic Entrepreneurship: creating value for individuals, organizations and society. The Academy of Management Perspectives, v. 15, n. 2, p. 57-75, 2011.

KAHIL, G. XP Investimentos compra portal financeiro InfoMoney. Exame.com. 08 set. 2011. Mercados. Disponível em: <https://exame.abril.com.br/mercados/xp-investimentos-compra-portal-financeiro-infomoney/>. Acesso em: $26 \mathrm{dez} .2017$.

MARKS, M. L.; MIRVIS, P. H. Joining Forces: making one plus one equal three in mergers, acquisitions and alliances. $2^{\text {nd }}$ ed. San Francisco: Jossey-Bass, 2010.

MEIO\&MENSAGEM. Abril Cria Market Place de Clubes de Assinatura. Meio \& Mensagem, São Paulo, 18 mai. 2016. Mídia. Disponível em: <http://www.meioemensagem.com.br/home/midia/2016/05/18/grupo-abril-cria-marketplace-de-clubes-de-assinatura.html>. Acesso em: 26 dez. 2017.

MIERZJEWSKA, B. I.; HOLLIFIELD, C. A. Theoretical Approaches in Media Management Research. In: ALBARRAN, A. B.; CHAN-OLMSTED, S. M.; WIRTH, M. O. (Org.). Handbook of Media Management and Economics. Abingdon: Routledge, 2006. P. 37-65. Disponível em: $<$ https:// www.routledgehandbooks.com/doi/10.4324/9781410615589.ch3>. Acesso em: 12 ago. 2016. 
NEVEU, E. Sociologia do jornalismo. São Paulo: Edições Loyola, 2006.

NEWS CORP. Delivering extraordinary experiences for our customers and consumers is at the heart of who we are. News Corp. Disponível em: $<$ https://newscorp.com/who-we-are/> Acesso em: 29 dez. 2017.

PICARD, R. G. Commercialism and Newspaper Quality. Newspaper Research Journal. v. 25, n. 1, p. 54-65, 2004.

PICARD, R. G. Why Journalists Deserve Low Pay. Robert Picard. Presentation to the Reuters Institute for Study of Journalism, RISJ Seminar, University of Oxford, maio/2009. Disponível em: < http://www.robertpicard.net/PDFFiles/whyjournalistsdeservelowpay.pdf $>$. Acesso em: 18 ago. 2017.

PLANALTO. Lei $\mathbf{n}^{\mathbf{0}}$ 6.404, de 15 de dezembro de 1976. Presidência da República. Disponível em: <http://www.planalto.gov.br/ccivil_03/leis/L6404consol.htm>. Acesso em: 26 dez 2017.

RODRIGUES, F. Dinâmica do processo decisório em equipe: análise temporal-ambiental. Tese de doutorado em Administração, Universidade de São Paulo, São Paulo, 2010.

RODRIGUES, F; ROCHA, T. V.; CAPOANO, E. Gestão e Decisões Estratégicas em Negócios de Mídia: um meta estudo. In: ENCONTRO DE ESTUDOS DE ESTRATÉGIA, 8., 2017, Curitiba. Anais eletrônicos... Curitiba: ANPAD, 2017. Disponível em: < http://www.anpad.org.br/ anpad/ eventos.php?cod_evento $=3 \&$ cod_evento_edicao $=87 \&$ cod_edicao_subsecao $=1424 \&$ cod_edicao_trabalho $=22528>$. Acesso em: 14 set. 2017.

SIEGERT, G., GERTH, M. A., RADEMACHER, P. Brand Identity-Driven Decision Making by Journalists and Media Managers: the MBAC model as a theoretical framework. International Journal on Media Management. v. 13, p. 53-70, 2011.

SILVA, E.S.; FIRMO, L.A.; SILVA, M.F.B.; e ALMEIDA, S.F. Fusões e Incorporações: decisões estratégicas que elevam o poder de uma organização. REBRAE - Revista Brasileira Estratégica, v.3, n.2, p. 161-169, Curitiba, maio/agosto de 2010.

TREVISAN, C. EUA derrubam regra relativa a concentração no setor de mídia. O Estado de S. Paulo, São Paulo, 16 nov. 2017. Economia \& Negócios. Disponível em: <http://economia. estadao.com.br/noticias/geral,estados-unidos-votam-hoje-regra-sobre-concentracao-na-midia,70002086067>. Acesso em: 26 dez. 2017. 
TURNER. Turner: about us. Disponível em: <https://www.turner.com/about-us>. Acesso em 22 out 2018 .

UOL. Grupo Record adquire 10\% das ações da filial da CNT Bahia. Na Telinha/UOL. 25 dez. 2014. Disponível em <http://natelinha.uol.com.br/noticias/2014/12/25/grupo-record-adquire-10-das-acoes-da-filial-da-cnt-na-bahia-83782.php>. Acesso em 26 dez. 2017.

WIIK, J. Journalism in Transition: the professional identity of Swedish Journalists. Tese de doutorado em Jornalismo e Comunicação, University of Gothenburg, 2010. Disponível em: <https:// gupea.ub.gu.se/bitstream/2077/21853/1/gupea_2077_21853_1.pdf >. Acesso em: 15 ago. 2017. 